\title{
Effective of Microwave-KOH Pretreatment on Enzymatic Hydrolysis of Bamboo
}

\author{
Zhiqiang $\mathrm{Li}^{1}$, Zehui Jiang ${ }^{1 *}$, Benhua Fei ${ }^{1}$, Yan $\mathrm{Yu}^{1}$, Zhiyong Cai ${ }^{2}$ \\ ${ }^{1}$ International Centre for Bamboo and Rattan, Beijing, China \\ ${ }^{2}$ Forest Products Laboratory, USDA Forest Service, Madison, USA \\ Email: lizq@icbr.ac.cn, ${ }^{*}$ jiangzehui@icbr.ac.cn, zcai@fs.fed.us
}

Received October 1, 2012; revised November 3, 2012; accepted November 19, 2012

\begin{abstract}
Bamboo, with its advantages of fast growth, short renovation, easy propagation and rich in cellulose and hemicellulose, is a potential feedstock for bioethanol or other biofuels production. The objective of this study was to examine the feasibility of microwave assistant $\mathrm{KOH}$ pretreatments to enhance enzymatic hydrolysis of bamboo. Pretreatment was carried out by immersing the bamboo in $\mathrm{KOH}(12 \%$ and $8 \% \mathrm{w} / \mathrm{w}$ bamboo) solutions and exposing the slurry to microwave radiation power of $400 \mathrm{~W}$ for $30 \mathrm{~min}$. Chemical composition of the pretreated substrates and spent liquor was analyzed. Pretreated substrates were enzymatic hydrolyzed, and glucose and xylose in the hydrolysate were analyzed. The results showed that the pretreated substrate with microwave assisted $\mathrm{KOH}$ had significantly higher sugar yield than the untreated samples. The fermentation inhibitors formic acid, furfural, HMF and levulinic acid were much lower than acid pretreatment reported.
\end{abstract}

Keywords: Bamboo, Microwave-KOH Pretreatment, Chemical Pretreatment, Enzymatic Hydrolysis, Bioethanol Production

\section{Introduction}

Bamboo, a perennial woody grass widely distributed in China, has an annual production of 1.356 billion culms [1]. Approximately 1500 commercial applications of bamboo have been identified. They may be divided up into the following broad categories: construction and reinforcing fibers; paper, textiles and board; food; combustion and other bioenergy applications [2]. Due to its advantages of fast growth, short renovation, and easy propagation, more and more attention has been paid to the applications in biobased energy field including bioethanol production [3-6].

As a lignocellulosic material, bamboo mainly consists of cellulose, hemicelluloses, and lignin, which chemically and physically associated with each other to form complex structure. Because of its tough matrix structure, raw bamboo is recalcitrant to cellulase systems for enzymatic saccharification. Pretreatment of bamboo is necessary to make bamboo substrate accessible to enzymes.

Because microwave irradiation has high heating efficiency, it has been used as an efficient pretreatment technique to enhance the enzymatic hydrolysis of biomass materials. Ooshima et al. [7] and Azuma et al. [8] initially reported microwave pretreatment of lignocelluloses.

\footnotetext{
${ }^{*}$ Corresponding author.
}

Recently, microwave-assisted alkali/acid/ $\mathrm{H}_{2} \mathrm{O}_{2}$ pretreatment of rice and wheat straw was investigated by Zhu et al. [9]. To our knowledge, the microwave-assisted alkali pretreatment of bamboo has not been investigated.

The object of this work was to preliminarily assess the effect of microwave-enhanced alkaline $(\mathrm{KOH})$ pretreatment process on the chemical composition and enzymatic hydrolysis of bamboo. In this study, the ground moso bamboo samples were subjected to microwave $\mathrm{KOH}$ pretreatment at a severe temperature. The chemical changes involved in the process were characterized with saccharides analysis in substrates and spent liquor. The fermentation inhibitors in the spent liquors were also investigated. The enzymatic hydrolysis of the pretreated bamboo after microwave alkali pretreatment was studied as well.

\section{Materials and Methods}

\subsection{Sample Preparation}

Moso bamboo (Phyllostachys heterocycla) was acquired from the central area of Florida, U.S.A. in the fall of 2009. Air-dry bamboo was milled using a hammer mill with a screen opening size of $2.0 \mathrm{~mm}$ before chemical pretreatment. The average moisture content of the ground air-dry bamboo was $6.93 \%(\mathrm{wt})$. The moisture content of 
the ground samples was measured in an oven at $103^{\circ} \mathrm{C} \pm$ $2^{\circ} \mathrm{C}$ for $24 \mathrm{~h}$. The ash and water-ethanol extractives in the bamboo were also determined.

\subsection{Microwave Pretreatment}

Bamboo samples were pretreated in a microwave accelerated reaction system manufactured by CEM Corporation (Model MARS, CEM Corporation, Matthews, North Carolina, and USA). This apparatus provided microwave radiation at 3 variable power levels ranging from 400 to $1600 \mathrm{~W}$. A bamboo sample of $8 \mathrm{~g}$ on an oven-dry (OD) basis was used for each pretreatment experiment. The samples were immersed in $50 \mathrm{~mL} \mathrm{KOH}$ solutions of $12 \%$ and $8 \%$ (w/w bamboo). The mixture was placed in a 100 $\mathrm{mL}$ vessel and positioned at the centre of a rotating circular ceramic plate in the microwave oven for treatment at the power level of $400 \mathrm{~W}$. The temperature was raised to $180^{\circ} \mathrm{C}$ in about $10 \mathrm{~min}$ and maintained for an additional $30 \mathrm{~min}$. After the pretreatment, waiting a few minutes to allow the temperature to drop down below $80^{\circ} \mathrm{C}$, and then separate the substrate and liquor by filtration. The liquor was stored in $4^{\circ} \mathrm{C}$ for the sugar and fermentation inhibitors analysis by high performance liquid chromatography (HPLC). The solid substrate was washed with water until the $\mathrm{pH}$ of the washing near neutral and then stored at $4^{\circ} \mathrm{C}$ for composition analysis and enzymatic hydrolysis. Each pretreatment was carried in duplicate; the average result was reported here.

\subsection{Enzymatic Hydrolysis}

Enzymatic hydrolysis was carried out in $150 \mathrm{~mL}$ flasks at $50^{\circ} \mathrm{C}$ on a shaking incubator (Thermo Fisher Scientific, Model 4450, Waltham, MA) at $220 \mathrm{rev} / \mathrm{min}$. Bamboo substrate equivalent to 0.8 g glucan was loaded in $40 \mathrm{~mL}$ of $0.05 \mathrm{M}$ sodium acetate buffer ( $\mathrm{pH} 4.8$ ). Approximately $1.5 \mathrm{mg}$ of tetracycline chloride was added to control the growth of microorganisms and prevent consumption of liberated sugars. Two enzymes, cellulase (15 FPU/g glucan) and $\beta$-glucosidase (30 IU/g glucan), were loaded into the flask. The hydrolysate was sampled at $1,3,6,12$, 24 and 48 hour to analyze glucose and xylose concentration.

\subsection{Analytical Methods}

Acid-insoluble lignin of original bamboo and $\mathrm{KOH}$ pretreated bamboo substrates was determined according to National Renewable Energy Laboratory (NREL) Analytical Procedure: Determination of Structural Carbohydrates and Lignin in Biomass (with modifications) [10]. Acid-soluble lignin in spent liuqors was measured at 205 $\mathrm{nm}$ on a UV-Visible spectrophotometer [11].

Carbohydrate compositions of the original bamboo, pretreated bamboo substrates and spent liquors were con- ducted using an improved high-performance anion exchange chromatography (Dionex HPLC system ICS-3000) equipped with integrated amperometric detector and Carbopac $^{\mathrm{TM}}$ PA1 guard and analytical columns at $20^{\circ} \mathrm{C}$.

Fermentation inhibitors including acetic acid, formic acid, furfural, levulinic acid and 5-hydroxylmethylfurural (HMF) were analyzed using the Dionex ICS-3000 equipped with a Supelcogel C-610H column at temperature $30^{\circ} \mathrm{C}$ and a UV detector at $210 \mathrm{~nm}$.

\section{Results and Discussion}

\subsection{Raw Bamboo Composition}

The chemical composition of the original bamboo is listed in Table 1. The data indicated that the dominant components in bamboo were glucan, lignin, and xylan. Cellulose (glucan) and hemicelluloses (xylan, arabinan, galactan, and mannan) accounted for more than $58 \%$ of the oven-dry weight of bamboo, making it a good potential feedstock for ethanol production. Xylose was the main sugar (91.5\%) for the hemicellulose fraction. Water-ethanol extractives of the bamboo are much higher (13.04\%) than those of wood and other bamboos [12]. But the ash was much lower than agricultural wastes [13]. The content of cellulose, hemicellulose, ash, and lignin was calculated on the water/ethanol extractives free bamboo material.

\subsection{Composition of Pretreated Bamboo and Spent Liquor}

Table 2 shows the chemical analysis of original raw bamboo, pretreated bamboo substrates and spent liquors after pretreatment. The pretreatment apparently dissolved structural components and more were dissolved with increased $\mathrm{KOH}$ concentration. The part of hemicellulose and lignin were dissolved, so glucose was enriched in the substrate. Therefore, the glucose percentage in the substrate pretreated with higher concentration of $\mathrm{KOH}$ was higher. The acid-insoluble lignin of $12 \% \mathrm{KOH}$ pretreated

Table 1. Chemical composition of oven-dry (OD) bamboo.

\begin{tabular}{cc}
\hline Composition & \% wt, od bamboo \\
\hline Cellulose as: & 37.21 \\
Glucan & 37.21 \\
Hemicellulose as: & 21.60 \\
Xylan & 19.77 \\
Arabinan & 0.99 \\
Galactan & 0.31 \\
Mannan & 0.53 \\
Ash & 1.41 \\
Lignin & 24.29 \\
Water-ethanol extractives & 13.04 \\
\hline
\end{tabular}


Table 2. Chemical analysis of original bamboo, pretreated bamboo substrates and spent liquors.

\begin{tabular}{|c|c|c|c|c|c|c|c|}
\hline & Arabinose & Galactose & Glucose & Xylose & Mannose & Acid-insoluble lignin & Acid-soluble lignin \\
\hline Original bamboo ${ }^{\mathrm{a}}, \%$ & $1.096 \pm 0.02$ & $0.34 \pm 0.02$ & $41.34 \pm 0.35$ & $21.96 \pm 1.03$ & $0.59 \pm 0.023$ & $22.84 \pm 0.31$ & $1.45 \pm 0.0$ \\
\hline $12 \% \mathrm{KOH}$ substrate ${ }^{\mathrm{a}}, \%$ & $1.33 \pm 0.12$ & $0.13 \pm 0$ & $49.91 \pm 0.18$ & $21.63 \pm 0.31$ & $\mathrm{ND}^{\mathrm{c}}$ & $21.11 \pm 1.01$ & $1.80 \pm 0.6$ \\
\hline $8 \% \mathrm{KOH}$ substrate ${ }^{\mathrm{a}}, \%$ & $1.22 \pm 0.03$ & $0.16 \pm 0.01$ & $45.72 \pm 1.47$ & $22.08 \pm 0.34$ & ND & $23.72 \pm 3.41$ & $1.59 \pm 0.17$ \\
\hline $12 \% \mathrm{KOH}$ liquor ${ }^{\mathrm{b}}$, g/L & $0.93 \pm 0.079$ & $0.048 \pm 0.0$ & $1.61 \pm 0.03$ & $3.66 \pm 0.22$ & $0.06 \pm 0.007$ & $\mathrm{NA}^{\mathrm{d}}$ & $6.92 \pm 0.58$ \\
\hline $8 \% \mathrm{KOH}$ liquor $^{\mathrm{b}}$, g/L & $0.70 \pm 0.19$ & $0.13 \pm 0.11$ & $1.36 \pm 0.02$ & $3.62 \pm 0.14$ & $0.03 \pm 0.02$ & NA & $5.72 \pm 0.31$ \\
\hline
\end{tabular}

Note: a—on the oven dried material; b—concentration in the liquor; c—not detected; $\mathrm{d}$ —not applicable.

substrate is less than that of $8 \% \mathrm{KOH}$ pretreated substrate, indicating more lignin was dissolved. This is consistent with the acid-soluble lignin in spent liquor, 6.92\% and $5.72 \%$, respectively.

\subsection{Fermentation Inhibitors}

Potential fermentation inhibitors formed during pretreatments are listed in Table 3, including Acid-soluble lignin, acetic acid. Other potential fermentation inhibitors, including furfural derived from pentoses, HMF from degradation of hexoses, and levulinic and formic acids from successive decomposition of HMF were not detected in the spent liquors. The total inhibitors were in lower concentrations in spent liquor than acid or steam pretreated spent liquors [14,15]. The concentration of acetic acid which released from acetyl groups on hemicelluloses was higher than acid pretreated spent liquor.

\subsection{Enzymatic Hydrolysis}

Glucose and xylose yields from enzymatic hydrolysis at different time are shown in Figure 1, respectively. Compared with untreated bamboo, microwave assisted-KOH pretreatment has distinctly improved the glucose and xylose yield. The glucose yield of unpretreated bamboo was only $2.41 \%$, and the xylose yield is $2.94 \%$. Glucose yield from enzymatic hydrolysis rose from $9.98 \%$ of $8 \%$ $\mathrm{KOH}$ pretreatment to $20.87 \%$ of $12 \% \mathrm{KOH}$ pretreatment at $48 \mathrm{~h}$. They were 4.1 folds and 8.7 folds improved respectively. The xylose yield was much higher than glucose yield, which were $40.56 \%$ of $8 \% \mathrm{KOH}$ pretreatment to $63.06 \%$ of $12 \% \mathrm{KOH}$ pretreatment at $48 \mathrm{~h}$. They were 13.8 folds and 21.4 folds improved respectively. For both glucose and xylose, the mild pretreatment gave lower sugar yield than the more severe pretreatment.

Table 3. Concentrations of major fermentation inhibitors in pretreatment spent liquor (unit: $g / L$ ).

\begin{tabular}{ccc}
\hline Inhibitors, g/L & $\begin{array}{c}\text { KOH liquor } \\
\mathbf{( 1 2 \% )}\end{array}$ & $\begin{array}{c}\text { KOH liquor } \\
\mathbf{( 8 \% )}\end{array}$ \\
\hline Acid-soluble lignin & 6.92 & 5.72 \\
Acetic acid & 7.27 & 7.03 \\
\hline
\end{tabular}

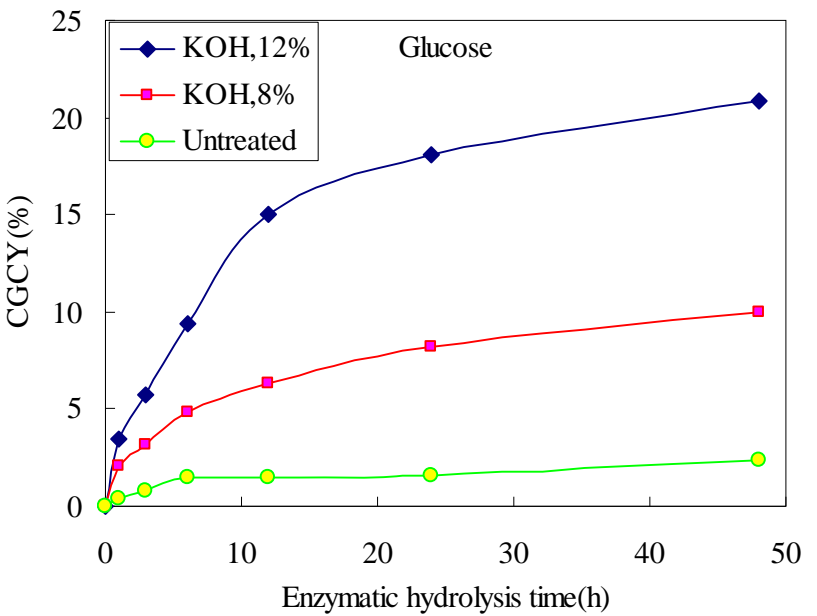

(a)

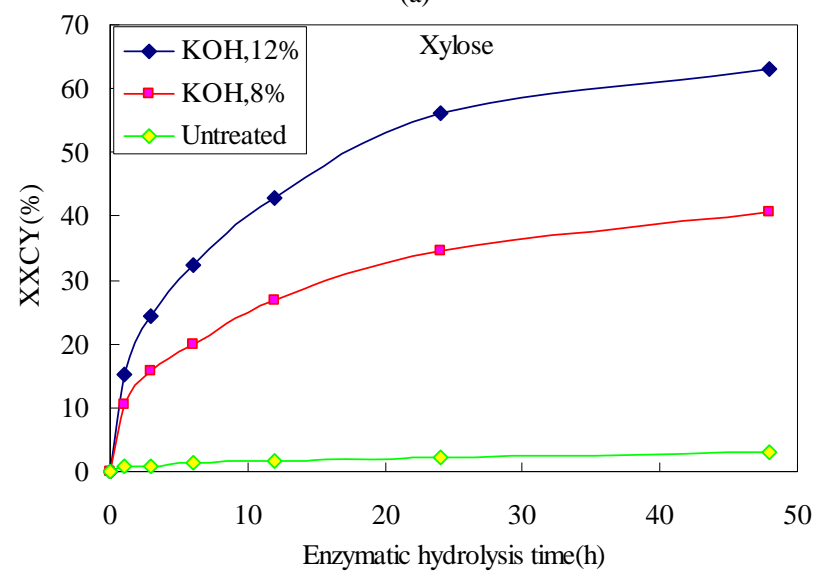

(b)

Figure 1. Comparisons of sugars yield on time-dependent enzymatic hydrolysability of microwave assistant $\mathrm{KOH}$ pretreated bamboo. CGCY: Cellulose-to-glucose conversion yield. XXCY: Xylan-to-xylose conversion yield.

\section{Conclusion}

Bamboo was rich in cellulose and hemicellulose fractions which were desirable components for ethanol production. Microwave assistant $\mathrm{KOH}$ pretreatment significantly removed the recalcitrance of bamboo and allowed enzymatic hydrolysis improved by 8.7 folds (20.87\%, glucose) and 20.5 folds (63.06\%, xylose), respectively, at $48 \mathrm{~h}$ compared 
with untreated bamboo (2.41\%, glucose; 2.94\%, xylose) with a cellulase loading of 15 FPU/g glucan. The fermentation inhibitors formic acid, furfural, HMF and levulinic acid were much lower than acid pretreatment.

\section{Acknowledgments}

The authors acknowledge Professor Xuejun Pan (Dept. of Bio- logical Systems Engineering, University of Wisconsin-Madison) for carrying out this research. The authors are grateful for the supports of National Project of Scientific and Technical Supporting Programs funded by Ministry of Science and Technology of China (No. 2012BAD54G01) and the Fundamental Re- search Funds for the International Centre for Bamboo and Rat- tan, Grant No. 1632012001.

\section{REFERENCES}

[1] State Forestry Administration, "China Forestry Development Report 2010," 2011.

http://www.forestry.gov.cn/portal/main/s/62/content-464039. html

[2] J. M. O. Scurlock, D. C. Dayton and B. Hames, "Bamboo: an Overlooked Biomass Resource?” Biomass and Bioenergy, Vol. 19, No. 4, 2000, pp. 229-244.

[3] M. Garcı'a-Aparicio, W. Parawira, E. V. Rensburg, et al., "Evaluation of Steam-Treated Giant Bamboo for Production of Fermentable Sugars," Biotechnology Progress, Vol. 27, No. 3, 2011, pp. 641-649. doi:10.1002/btpr.580

[4] W. Leenakul and N. Tippayawong, "Dilute Acid Pretreatment of Bamboo for Fermentable Sugar Production,” Journal of Sustainable Energy \& Environment, Vol. 1, No. 3, 2010, pp. 117-120.

[5] T. J. B. De Menezes, C. L. M. Dos Santos and A. Azzini, "Saccharification of Bamboo Carbohydrates for the Production of Ethanol," Biotechnology and Bioengineering, Vol. 25, No. 4, 1983, pp. 1071-1082.

[6] T. Shimokawa, M. Ishida, S. Yoshida, et al., "Effects of Growth Stage on Enzymatic Saccharification and Simul- taneous Saccharification and Fermentation of Bamboo Shoots for Bioethanol Production,” Bioresource Technology, Vol. 100, No. 24, 2009, pp. 6651-6654.

[7] H. Ooshima, K. Aso, Y. Harano and T. Yamamoto, "Microwave Treatment of Cellulosic Materials for Their Enzymatic-Hydrolysis,” Biotechnology Letters, Vol. 6, No. 5, 1984, pp. 289-294. doi:10.1007/BF00129056

[8] J. I. Azuma, F. Tanaka and T. Koshijima, "Enhancement of Enzymatic Susceptibility of Lignocellulosic Wastes by Microwave Irradiation,” Journal of Fermentation Technology, Vol. 62, No. 4, 1984, pp. 377-384.

[9] S. D. Zhu, Y. X. Wu, Z. N. Yu, Q. M. Chen, G. Y. Wu, F. Q. Yu, C. W. Wang and S. W. Jin, "Microwave-Assisted Alkali Pre-Treatment of Wheat Straw and Its Enzymatic Hydrolysis,” Biosystems Engineering, Vol. 94, No. 3, 2006, pp. 437-442. doi:10.1016/j.biosystemseng.2006.04.002

[10] A. Sluiter, B. Hames, R. Ruiz, C. Scarlata, J. Sluiter, D. Templeton and D. Crocker, "Determination of Structural Carbohydrates and Lignin in Biomass," National Renewable Energy Laboratory, Golden, 2008.

[11] C. W. Dence, “The Determination of Lignin,” In: C. W. Dence, Ed., Methods in Lignin Chemistry, Springer-Verlag, Berlin, 1992, pp. 33-61.

[12] J. M. O. Scurlocka, D. C. Daytonb and B. Hamesb, “Bamboo: An Overlooked Biomass Resource?” Biomass and Bioenergy, Vol. 19, No. 4, 2000, pp. 229-244.

[13] N. Sarkar, S. K. Ghosh, S. Bannerjee and K. Aikat, "Bioethanol Production from Agricultural Wastes: An Overview,” Renewable Energy, Vol. 37, No. 1, 2012, pp. 1927.

[14] L. Shuai, Q. Yang, J. Y. Zhu, F. C. Lu, P. J. Weimer, J. Ralph and X. J. Pan, "Comparative Study of SPORL and Dilute-Acid Pretreatments of Spruce for Cellulosic Ethanol Production,” Bioresource Technology, 2010, Vol. 101, No. 9, pp. 3106-3114.

[15] M. Garcı'a-Aparicio, Wi. Parawira, E. Van Rensburg, D. Diedericks, et al., "Evaluation of Steam-Treated Giant Bamboo for Production of Fermentable Sugars," Biotechnology Progress, Vol. 27, No. 3, 2011, pp. 641-649. doi:10.1002/btpr.580 